\title{
Reducing carbon emissions related to the transportation of aggregates: is road or rail the solution?
}

\author{
Chengchoa.Zuo ${ }^{1,2}$, Mark Birkin ${ }^{2}$, Graham Clarke $^{2 *}$, Fiona McEvoy $^{3}$, Andrew Bloodworth $^{3}$ \\ ${ }^{1}$ College of Public Administration, Huazhong Agricultural University, Wuhan, 430070, China, P.R. \\ ${ }^{2}$ School of Geography, University of Leeds, Leeds, LS2 9JT, United Kingdom \\ ${ }^{3}$ British Geological Survey, Keyworth, Nottingham, NG12 5GG, United Kingdom
}

\begin{abstract}
The transportation of aggregates from quarry to production site raises significant concerns over carbon emissions. A considerable body of literature argues that if more freight could be carried on the rail network, substantial reductions in carbon footprints could be made. This paper describes a modelling framework for estimating the spatial transfer or movement of aggregates between quarries in England and Wales and local authority districts (demand zones). A key part of this framework is the estimation of the carbon emissions associated with both road and rail travel. Once built and calibrated, the model is used for a variety of what-if scenarios relating to the increased use of rail (which includes the necessary construction of new uplifting facilities as well as the number of rail-linked quarries) against future road haulage undertaken through a modernised vehicle fleet. The latter is shown to provide a more realistic and economic solution to reducing carbon emissions associated with the transportation of aggregates.
\end{abstract}

Keywords : primary aggregates, microsimulation, carbon emission, spatial interaction model

\section{Introduction}

All sectors of the UK economy have a responsibility to reduce their carbon footprint given the overall commitment of different UK governments to various international protocols and 
domestic policies (Department for Environment, Food and Rural Affairs 2005; Department for Energy and Climate Change 2009). The UK aggregates market produces around 1.7 million tonnes of $\mathrm{CO}_{2}$ per year (Minerals Product Association 2010 and recent research shows that the transportation of aggregates is responsible for around $40 \%$ of the carbon footprint associated with this industry (Minerals Product Association 2010, Department for Energy and Climate Change 2009, Zuo et al. 2013). A series of research studies have suggested that modal shift from road to rail could be a positive initiative to improve the environmental footprint of transporting aggregates, as the overall environmental impact per mile for rail is significantly lower than for road transport (Chapman, 2007; Department for Transport 2008). However, research conducted by Boston Consulting Group (2009) argued that despite the financial and environmental benefits of rail transport, most UK aggregates are transported by road because the greater density of the road network offers far greater flexibility and access to customers. The BCG report does point out that investment in rail could be attractive for large quarries with extensive production volumes. That said, the report also suggested that improvements in the environmental performance of the road vehicle fleet might be a feasible and efficient way to reduce the carbon emission and other environmental impacts of the transport of aggregates. A 'Synthesis Report' published in 2012 by 'Sustainable Aggregates' (a research programme funded by the Aggregates Levy Sustainable Fund) set both to 'maintain and increase the proportion of land-won aggregates by rail' and to make 'improvements in vehicle to reduce the impacts of road haulage' as two (out of ten) key issues for policymakers and decision-takers (Hicks, 2012).

To date, there are few examples of model-based systems being developed to provide detailed evidence regarding the environmental impacts of alternative policies regarding different modes of travel for freight transportation. In this paper, we will first describe a model to replicate the flows of aggregates from source (quarry) to destination (major UK regions). The model has been developed in partnership between the British Geological Survey (BGS) and the University of Leeds to address challenges in scenario-based planning of minerals transfer in the UK aggregates industry (see Zuo et al 2013 for more background on the collaborative project). The approach uses a spatial interaction model to match the supply and demand of aggregates, and subsequently estimates the carbon emissions (based on the mode and distance travelled) associated with the movement of those aggregates. It incorporates a simulation model designed to forecast the ageing of the fleet of trucks over time and the gradual upgrading of this fleet to higher standards of European specification in relation to carbon emissions. Thus, we can then 
test the impacts on carbon emissions of more aggregates being transferred to rail, versus more aggregates being carried on more modern trucks.

The combination of disparate data sources used in conjunction with model-based spatial analytics for scenario planning characterises this exercise as a spatial decision support system (SDSS) for minerals planning. This approach permits the spatial disaggregation of the supply chain for aggregates in order to facilitate evaluation of the environmental impacts. This adapts methods which has been widely implemented for retail and service planning (Birkin et al, 2010), but the deployment of a SDSS for scenario analysis for the UK minerals sector is entirely novel, and could be applied more widely to commodities and other industrial sectors. It can be used to simulate and quantify the impacts of a variety of potential policy scenarios to help reduce the carbon emissions associated with the movement of aggregates. We will argue that the conclusions are clear but to some extent counter-intuitive. The adoption of a spatial perspective and associated analytical methods is therefore essential in understanding the impacts of policy alternatives.

The rest of the paper is structured as follows. In section 2 we describe the structure of the UK aggregates market and discuss elements related to its carbon footprint. Section 3 then introduces the model and discusses its calibration. An extension to the spatial interaction modelling framework is the addition of a simulation model of the road fleet used to transport aggregates is described in section 4 . In section 5 we run a series of scenarios for first increasing rail capacity and hence moving more aggregates across England and Wales by rail. In section 6 we then look at whether we could make more significant emission reductions by improving the efficiency of the road fleet used for the haulage of aggregates. This involves implementing the microsimulation model of the fleet market and examining the impact of gradually renewing and upgrading the fleet of trucks over time. The final section of the paper provides a discussion of the significance of the substantive results from the analysis. It will also consider the importance of possible limitations in the structure of the models and their implementation and the possibilities for further model enhancement as well as further work using the current models or their successors.

\section{Aggregates industry in the UK and its carbon footprint}


Aggregates are widely used in the UK construction industry, especially for road repair and construction (32\%) and new house build (28\%) (Strategic Rail Authority 2005). The BGS define aggregates as being 'hard, granular materials which are suitable for use either on their own or with the addition of cement, lime or a bituminous binder in construction' (Highley, et al., 2007). Although England and Wales are largely self-sufficient for primary aggregates, there are significant regional imbalances in both the location of supply points (the UK quarries) and demand points (major areas of construction, namely towns and cities) which means that large inter-regional movements or transfers of aggregates are required. For example, in the south east of England and London, demand is generally three times that of the supply available within the two regions. In contrast, some regions have greater supply than demand, notably in more rural regions such as the North and East Midlands and the south-west England and Wales. Figure 1 shows the geography of supply and demand in more detail.

More than $90 \%$ of aggregates are currently transported by road (British Geological Survey 2006). Each year, only 13 million tonnes (less than 10\%) are moved by rail (Quarry Products Association 2006; British Geological Survey 2006; Mineral Products Association 2009, 2011, 2013, 2015) with 2 million tonnes additionally moved by coastal or inland waterway (British Geological Survey 2006). These non-road transport modes are associated with longer average transport distances. According to the Mineral Products Association (2009) the average transport distance in England had reached $144 \mathrm{~km}$ for rail and $35 \mathrm{~km}$ for road by 2007 . It is widely accepted that rail provides lower $\mathrm{CO}_{2}$ emissions (per tonne kilometre) than road transportation, but whether substantial $\mathrm{CO}_{2}$ savings can be made by increasing the rail network (thus taking more freight off the road) or by improving/reducing the $\mathrm{CO}_{2}$ emissions from the road fleet is a question which has so far been harder to answer in the literature. This paper helps to answer this question using the transportation of aggregates as an example. 

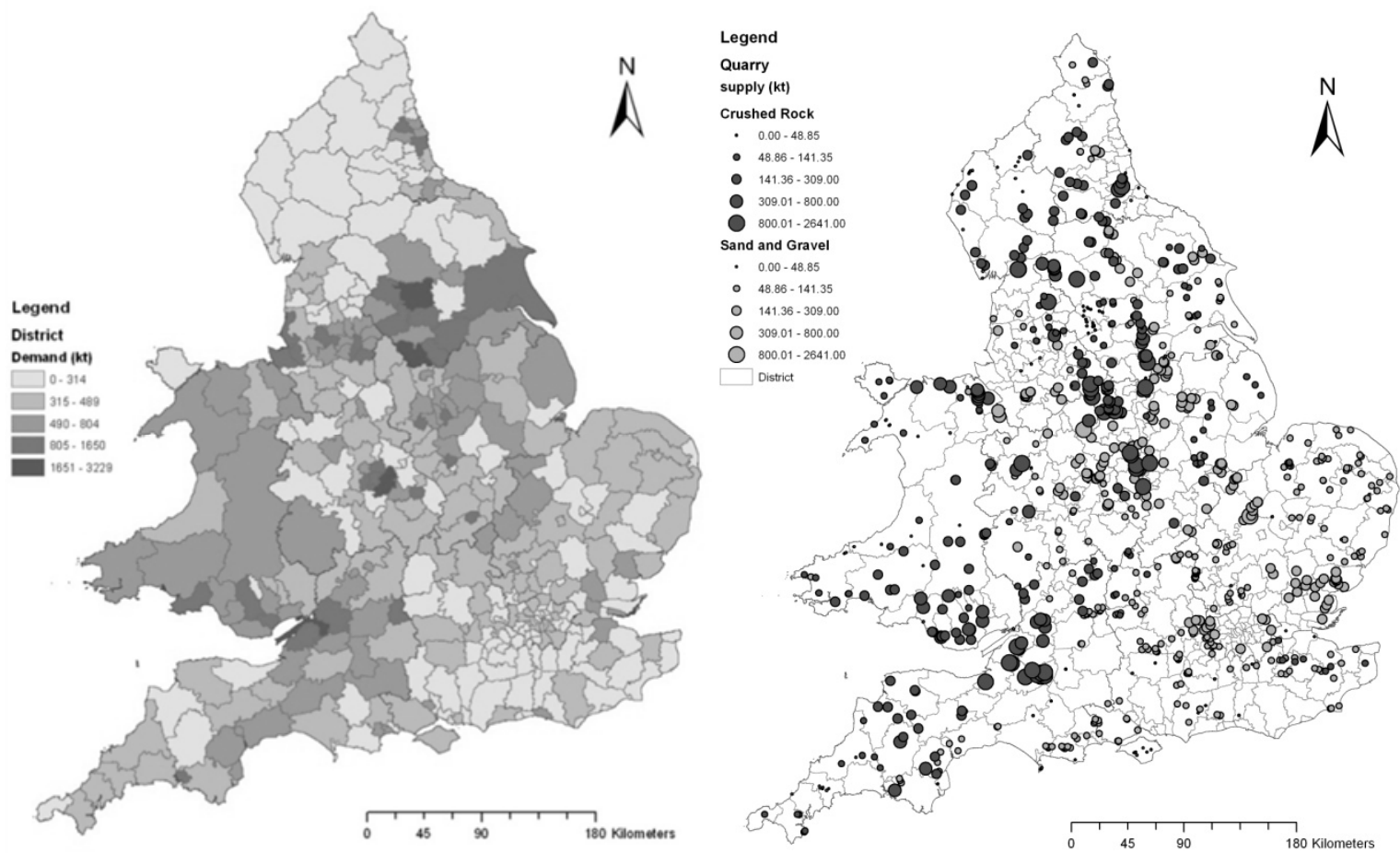

Figure 1: Demand and output of aggregate at quarry-district level in England and Wales

\section{A model for transporting aggregates}

\subsection{Framework}

A central objective of this paper is to produce estimates of the carbon emissions associated with the transfer of aggregates in the UK under alternative scenarios concerning mode of travel. In order to evaluate such scenarios the transportation process needs to be simulated in detail.

Traditionally, models developed for strategic freight transport forecasting follow a four-step modelling structure which combines trip generation, distribution, modal split and assignment (de Jone et al., 2004, 2013, Chow et al., 2010). In the modelling framework adopted here, these elements are combined in the following way. First, the individual elements of supply and demand are estimated. Then, we determine the trip costs for the different transport alternatives in the network. A doubly-constrained spatial interaction model is specified and calibrated to distribute the flows between origins and destinations. The modal split is determined within the SIM according to the availability and cost of transport connections between origin-destination 
pairs. Then the aggregate flows are assigned to each individual network segment. Finally, the carbon emissions are calculated based on the movements along the various networks. These stages will now be outlined in more detail.

First, we disaggregate individual flows into a point of origin and a point of destination in order to assess the impact of each transfer. In terms of aggregate supply, the obvious unit of analysis is the individual quarry. Information about quarries is available in a database known as 'BritPits' (Cameron, 2011), in which 931 locations are uniquely identified. For reasons of confidentiality the output of each quarry is suppressed and production is only known for each of 183 Mineral Planning Areas (MPAs). In addition, the location of 27 super-producers is known, each accounting for at least 1 million tonnes of annual output. For the purpose of the model, it is assumed that the production of each of these large quarries is $1 \mathrm{mt}$ and this is subtracted from the MPA total. The remaining production is then distributed evenly between the other quarries in each MPA.

The demand for aggregates is distributed between a very large number of consumers and construction projects. However the only data on consumption of aggregates that can be readily accessed from published sources is published for each of the 10 Government Office Regions (GORs). This level of detail is manifestly insufficient to represent the diversity of consumption between construction projects which may be hundreds of miles apart within a single GOR. To address this problem, the demand in each region is broken down in proportion to the number of people in each constituent Local Authority District (LAD), totalling 376 in England and Wales. The populations of the LADs are derived from the 2011 Census. Hence, there is a matrix of 931 supply points and 376 demand zones, providing an array of around 350,000 possible individual transfers. Further disaggregation of the demand zones would add extra detail, but is unlikely to materially affect the outcomes of this analysis.

For each of the individual origin-destination pairs three options are considered for the transportation of aggregates: i) the locations are connected by road only; ii) the origin location is linked directly to the rail network, from which aggregates are transferred to one of the 63 UK rail depots, and then allocated to its final destination by road; iii) the origin node is connected to a rail depot by road, aggregates are transferred between rail depots, and the product is again allocated to its final destination by road. Due to the lack of uploading facilities in most of the rail depots in the UK, only the first two options are considered in the baseline model. However, the third scenario will be tested as a what-if model run in Section 4.4. The 
destination points are considered as the centroids of the LADs and none of these are connected directly to the rail network. This mirrors the fact that in reality further transhipment is always needed from the endpoint of a rail trip to the point of consumption. The cost of downloading from rail to the road network is given by the 'transhipment cost' (defined below). Figure 2 illustrates the two principal transport modes for the transportation of aggregates in England and Wales used in the baseline model.

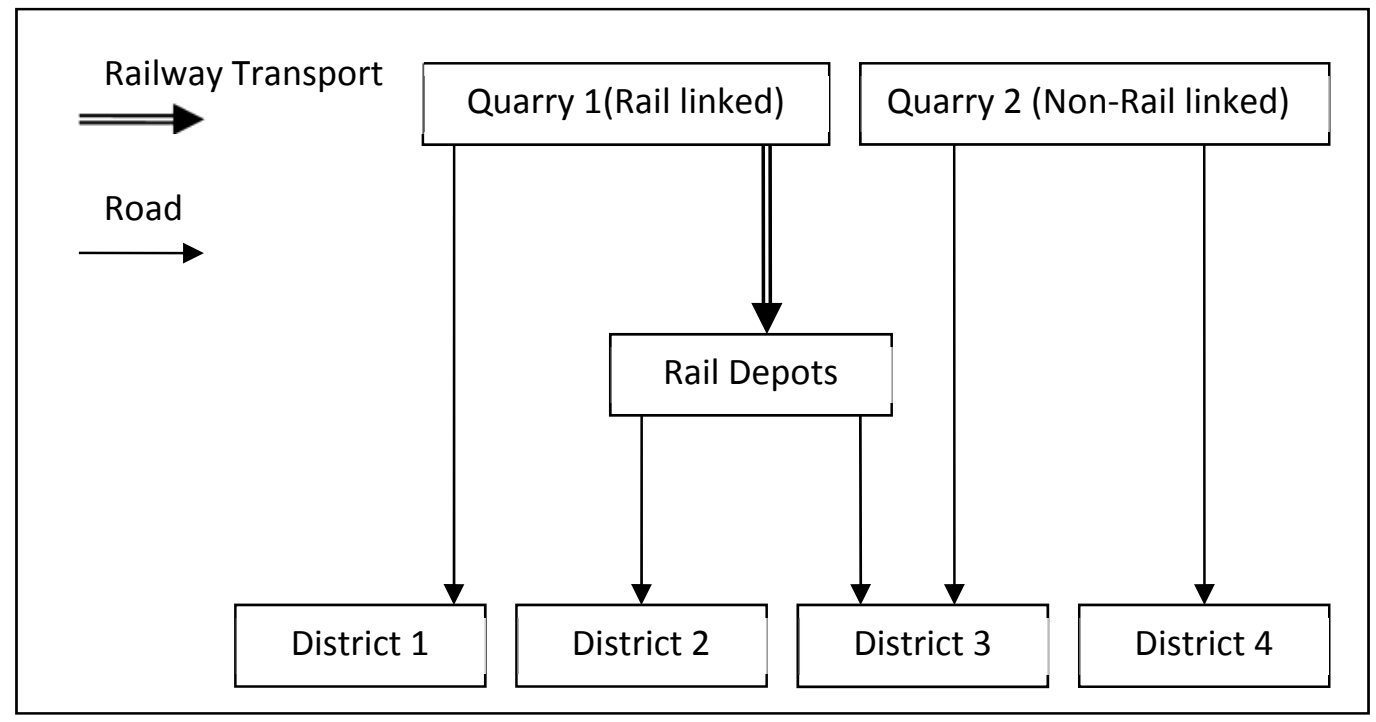

Figure 2: The two transport modes for transporting aggregates in England and Wales used in the baseline model

The flows for each origin-destination pair are estimated using a two stage process. In the first stage, a unit transport cost is calculated for each of the available transport options and the least cost option is selected. The road network comprises all major roads and highways; the rail network consists of every individual track segment with 63 depots and 13 rail-linked quarries. Through spatial analysis, the minimum network distance was identified between every origindestination pair on the road network, and between every combination of rail-linked quarries and rail depots on the railway network. The nearest depot is always used when the rail and road networks are combined. Both the road and rail networks were assembled from the Ordnance Survey Meridian 2 dataset. The Network Analyst feature in ArcGIS 9.3 was used to underpin the distance calculations.

The general form of the distance deterrence function $\mathrm{d}_{\mathrm{ij}}$ is given as follows:

$$
\mathrm{d}_{\mathrm{ij}}=\min \left\{\mathrm{d}_{i j}^{\text {road }} ; \mathrm{d}_{i k}^{\text {road }}+\mathrm{d}_{1}^{t}+\mathrm{RC}^{*} \mathrm{~d}_{k m}^{\text {rail }}+\mathrm{d}_{2}^{t}+\mathrm{d}_{m j}^{\text {road }}\right\}
$$


where $\mathrm{d}_{i j}^{\text {road }}$ is the distance of road haulage from origin $\mathrm{i}$ to destination $\mathrm{j} ; \mathrm{d}_{1}^{t}$ and $\mathrm{d}_{2}^{t}$ are respectively the transhipment costs for upload to and download from the rail network which are measured by road distance equivalent; $\mathrm{d}_{i k}^{\text {road }}$ and $\mathrm{d}_{m j}^{\text {road }}$ represent the road transport distance from quarry $\mathrm{i}$ to rail depot $\mathrm{k}$ and from depot $\mathrm{m}$ to destination $\mathrm{LAD} \mathrm{j} ; \mathrm{d}_{\mathrm{km}}^{\text {rail }}$ is the rail transport distance between rail depot (rail linked quarry) $\mathrm{k}$ and rail depot $\mathrm{m}$, and $\mathrm{RC}$ is the 'relative cost' of rail transfer against road.

For the aggregates industry, the monetary cost of transport is much more important than other factors (i.e. the benefit of additional modal options, modal capacity, time savings etc.) when looking at modal choice. Therefore, in order to simplify the calculation, in this paper, an 'allor-nothing' choice model was used instead of a logsum type measurement which is commonly used in passenger transport models.

In the second stage, the flows between each origin-destination pair are then estimated using a doubly-constrained spatial interaction model (SIM). Demand is satisfied by the available supply according to the cost of transport derived at Stage One, subject to a dispersion parameter $\beta$ (which allows for the possibility that realised flows are not 'cost-minimising'):

$$
\begin{gathered}
\widehat{m}_{i j}=A_{i} O_{i} B_{j} D_{j} f\left(d_{i j}\right), \quad(i, j=1,2, \ldots, r, i \neq j) \\
\sum_{j} \hat{m}_{i j}=O_{i} \quad(i=1,2, \ldots, r) \\
\sum_{i} \hat{m}_{i j}=D_{j} \quad(j=1,2, \ldots ., r) \\
A_{i}=1 / \sum_{j} B_{j} D_{j} f\left(d_{i j}\right) \quad(i=1,2, \ldots, r) \\
B_{j}=1 / \sum_{i} A_{i} O_{i} f\left(d_{i j}\right) \quad(j=1,2, \ldots, r) \\
f\left(d_{i j}\right)=\exp \left(-\beta \cdot d_{i j}\right)
\end{gathered}
$$

where $\widehat{\mathrm{m}}_{\mathrm{ij}}$ is the predicted movement of aggregates from origin quarry $\mathrm{i}$ to destination district $\mathrm{j} ; \mathrm{A}_{\mathrm{i}}$ and $\mathrm{B}_{\mathrm{j}}$ are balancing factors; $\mathrm{O}_{\mathrm{i}}$ is the volume of aggregates produced in quarry $\mathrm{i} ; \mathrm{D}_{\mathrm{j}}$ represents the total demand for aggregates in district $\mathrm{j}$; and $\mathrm{d}_{\mathrm{ij}}$ is the travel cost between each origin-destination pair estimated as in equation 1. 


\subsection{Model calibration}

In order to implement the model described in Section 3.1 above, three unknowns - the dispersion parameter $(\beta)$, the Relative Cost (RC) and the Transhipment Cost (t1 and t2) - need to be estimated for each of the two products.

The cost for rail transport can be expressed as a linear model where transhipment cost has a contribution to the final cost (in addition to the cost of transport itself). In the baseline model, we assumed that none of the rail depots has an uploading facility for aggregates in particular, thus only the aggregates extracted directly at a rail-linked quarry has the opportunity to be delivered by rail. In this case, $\mathrm{t} 1$ is given as $+\infty$ to prevent uploading activities where none exist. According to Harris and McIntosh (2003), the transhipment cost (t2) in equation (1) can be estimated as $30 \mathrm{~km}$ road distance equivalent.

Relative cost (RC) in equation (1) is a factor which converts the rail transport distance to road transhipment cost equivalent. This is calibrated by using the current market share of rail transportation against road transportation. A higher RC value will lead to a higher cost for rail transport which reduces the competitiveness of rail transportation, then reduce the market share of rail transport accordingly. In practise, an exhaustive search method was used to identify most suitable RC value between 0 and 1 at a 0.01 precision level. According to the Quarry Production Association (2006) about 6.9\% of the aggregates produced in Great Britain (about $13 \mathrm{~m}$ tonne) are transported by railway in 2005. Numerical experiments with the baseline model indicated that a Relative Cost of 0.31 (i.e. rail cost per $\mathrm{km}$ is $31 \%$ that of road) provides a similar split for 'road versus rail' and thus $\mathrm{RC}=0.31$ is the parameter value adopted for the baseline model.

The $\beta$ value in Eq.7 in the model measures the importance of distance. Thus a high beta value would replicate a system of interest containing many short distance movements. The Standard Root Mean Square Error and $\mathrm{R}^{2}$ were calculated to measure the goodness-to-fit between the modelled and observed flows of aggregates in order to determine the optimal $\beta$ value. In practice, a number of experiments were taken with different $\beta$ values and the corresponding flows of aggregates were calculated based on Eq. 2 at the quarry-LAD level. Because the observed flows of aggregates are only available at Government Office Region (GOR) level (DCLG, 2007), the quarry-LAD level flows have to be aggregated to the GOR level first. 
According to the experiment results, a best-fit $\beta$ value of 0.15 was estimated for which $R^{2}$ achieved a value of 0.9946 and SRMSE was low at 0.2483 .

\subsection{Estimation of carbon emissions associated with the transportation of aggregates}

The SIM produces estimates of the flow of aggregates between each origin and destination represented by the volume and distance the aggregates are transported between each quarry and LAD. The next step is to estimate the carbon emissions based on these flows of aggregates.

For the purpose of the baseline model, freight emissions are assumed to be linear to both volume and trip distance and are sourced from Defra's Greenhouse Gas (GHG) Conversion factors (Department for Environment, Food and Rural Affairs 2008). Rail emissions are averaged at $31.9 \mathrm{gCO}_{2} /$ tonne* $\mathrm{km}$ assuming an average emission level for diesel locomotives which account for more than $90 \%$ of aggregates transfer. Road vehicle emissions are calculated by averaging GHG conversion factors across the range of articulated and rigid vehicles of different sizes, in proportion to the composition of the UK HGV fleet (Department for Transport 2008), giving an average of $120.4 \mathrm{~g} \mathrm{CO}_{2} / \mathrm{tkm}$.

\subsection{Baseline model results}

From the baseline model, $96.9 \mathrm{mt}$ of crushed rock (CR) and $58.9 \mathrm{mt}$ of land-won sand and gravel (LSG) are transported in the UK, and all of these volumes are at least partially transferred by road, giving an average trip distance of $45 \mathrm{~km}$ per trip. According to the model outputs, 65,450individual trips are required for crushed rock, producing a $\mathrm{CO}_{2}$ emission of $483.63 \mathrm{kt}$. Similarly, the carbon emission of the road transport of land-won sand and gravel is calculated as $229.07 \mathrm{kt}$. The $11.77 \%$ of the (land-won) aggregates transported by railway produce $61.19 \mathrm{kt}_{\text {of }} \mathrm{CO}_{2}$. As only $2 \mathrm{LSG}$ quarries are currently rail-linked in the UK, the amount of $\mathrm{CO}_{2}$ associated with rail transported LSG is quite limited- $0.44 \mathrm{kt}$. Table 1 summarizes the carbon emissions associated with the transport of aggregates under the baseline scenario. 
Table 1: Summary of Carbon Emission Associated with Transport of Aggregates under Baseline Scenario

\begin{tabular}{lrr}
\hline & \multicolumn{1}{c}{ CR } & \multicolumn{1}{c}{ LSG } \\
\hline $\mathrm{CO}_{2}$ Rail (kt) & 61.19 & 0.44 \\
$\mathrm{CO}_{2}$ Road $(\mathrm{kt})$ & 422.43 & 228.63 \\
$\mathrm{CO}_{2}$ Total $(\mathrm{kt})$ & 483.63 & 229.07 \\
\hline
\end{tabular}

\section{A simulation model of the road fleet}

As noted in the introduction, to estimate the carbon footprint associated with transporting aggregates by road we need to build a simulation model which can first replicate the existing truck fleet. The road fleet comprises a diverse array of vehicles which are heterogeneous in their size, age, body type and emission levels. The composition of the fleet (and its changing characteristics) has an important bearing on the relative efficiency of road as a transport mode in terms of carbon footprint. Once the simulation model is built, it is possible to experiment with modelling the impact of the introduction of new vehicle types. The process of (micro)simulation has been extensively applied in economic and socio-demographic models, including models of traffic demand (e.g. Neffendorf et al., 2001 Vovsha et al 2002, Liu 2005). However, there are few examples of specifically modelling the type of vehicles in the road haulage sector (though see interesting comparisons in Musti \& Kockelman 2011 and Cortes et al, 2005). To build the baseline microsimulation model, we simulate the entire fleet of heavy good vehicles (HGVs): 436,200 individual vehicles. Each vehicle is then represented by a single record consisting of the following basic attributes (Table 2)

Table 2 Attributes of the Synthetic Vehicle Records

\begin{tabular}{ll}
\hline Attributes & Descriptions \\
\hline ID & A unique number for each individual HGV \\
Body Type & Rigid or Artic \\
GVW & \\
Year of Registration & \\
Emission Standard & Euro I, II, III, IV, or V \\
Age & Modelling Year - Year of Registration \\
\hline
\end{tabular}


The registration year and gross vehicle weight (GVW) associated with body type split are based on the Road Freight Statistic data (Department for Transport 2008). Figures 3 and 4 show the key statistics of the modelled HGV populations.
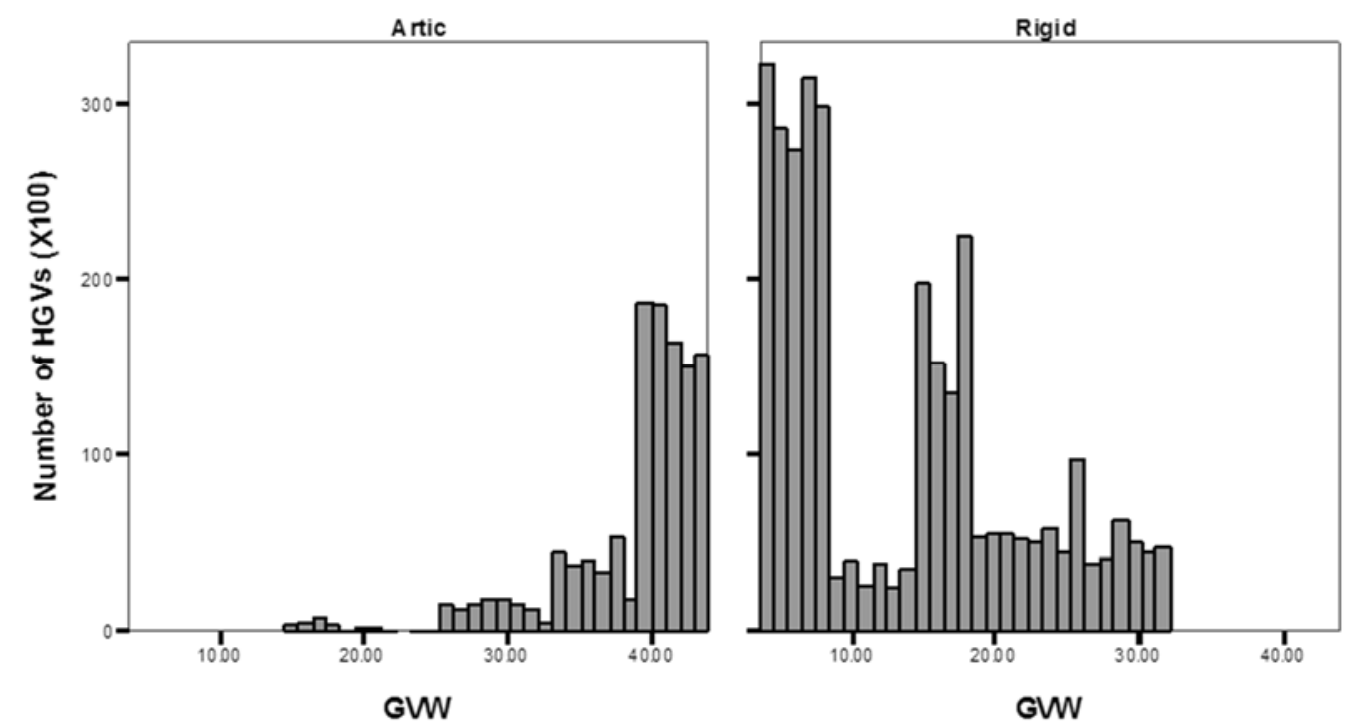

Figure $3 \mathrm{GVW}$ (in tonnes) associated with body type of the modelled HGV population

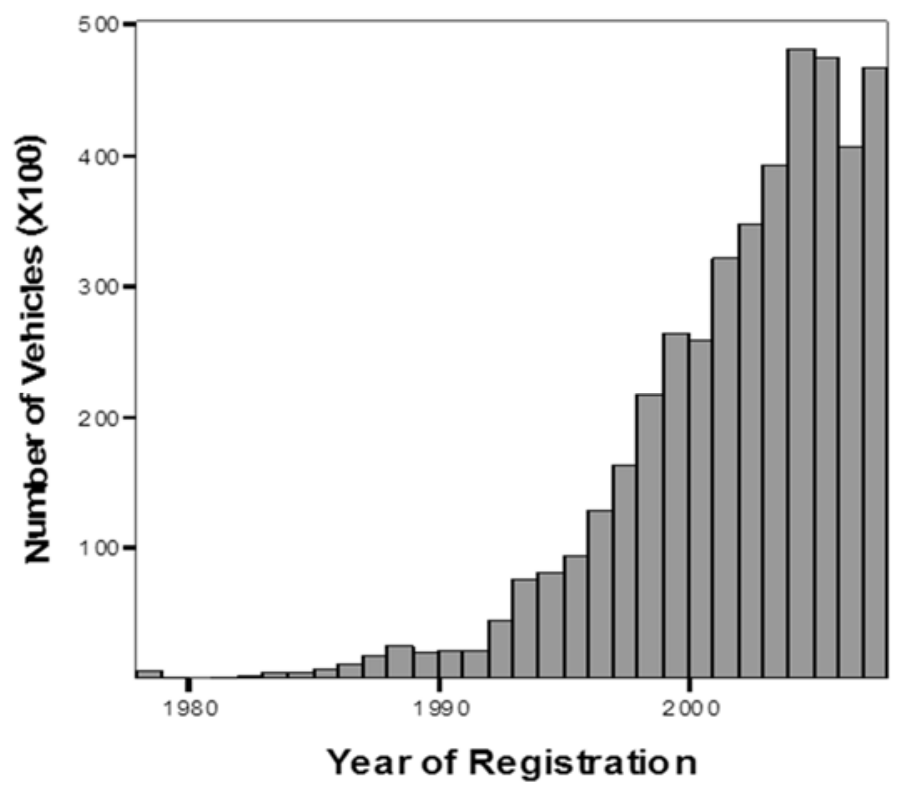

Figure 4 Year of Registration of modelled HGV population

In addition to the body type, GVW and emission standard, which are all required in the emission model, the age of each vehicle was also simulated. In computation terms, each single trip of aggregates between a quarry and district was identified as a task, with the following 
attributes: type of aggregate, volume of aggregate, travel distance associated with transport mode and road condition (e.g. urban/rural). Given this information, the model uses a Monte Carlo Sampling technique to select vehicles from the synthetic vehicle pool and then estimates the carbon emissions based on each individual journey based on that fleet selection. First, the model randomly assigns a vehicle from the synthetic vehicle pool to carry out the task. This vehicle's capacity is hopefully larger than the predicted flow but if the vehicle cannot complete the task in one journey, the model randomly picks another vehicle to supplement the first vehicle. This simple procedure of adding an additional vehicle where necessary could be replaced in future with a more detailed replacement procedure based on lorry availability and size. This process is repeated until all the aggregates are moved. Then, the carbon emissions can be calculated based on these individual vehicle journeys.

The carbon emission associated with the return trip was also estimated in the model. On its return trip, the vehicle is assumed to be empty, with reduced emission levels between $50 \%$ (for a $33 \mathrm{t}$ articulated tipper) and $83 \%$ (for a $3.5 \mathrm{t}$ rigid vehicle) of those when fully laden (Defra, 2008). The carbon emission was then calculated based on the additional journey from the destination to the quarry with the reduced emission level.

For each vehicle, the $\mathrm{CO}_{2}$ and other atmospheric pollutants are emitted as a result of combustion and other processes. In order to identify the most important factors which need to be considered in estimating the carbon emissions from each type of $\mathrm{HGV}$, a range of existing UK models were reviewed (for a wider ranging review of measuring $\mathrm{CO}_{2}$ emissions from road freight transport see McKinnon and Piecyk (2009)). DEFRA's Greenhouse Gas (GHG) model includes a general carbon emission factor for all HGVs with fixed values for five different vehicle classes (by weight and body type). These factors may vary by loading, but are independent of vehicle speed and emission standards. In addition, The National Atmospheric Emissions Inventory (NAEI) provides a general average speed and emissions function for different vehicle categories which discriminates between a variety of passenger vehicles. However, only two heavy vehicle types are stipulated - rigid or articulated. DfT's NERA report (Department for Transport 2005) includes a relational database distinguishing 33 different HGV types by body type, vehicle weight and axle configuration. It includes 8 carbon emission factors for eight different average speeds and scaling factors are supplied for Euro III and IV Standard vehicles. Finally, TRL (Boulter et al, 2009) provides vehicle emission factors for 91 different vehicle types by body type and vehicle weight and emission standards. 
Amongst these models, those of NERA and TRL are the most detailed and flexible and their values were used in the simulations reported below.

\section{What-if modelling (1): increasing usage of rail transport}

\subsection{Overview}

As noted in section 1, the carbon footprint of the transfer of aggregates is demonstrably less by rail than by road. Rail transport is commonly regarded as a transport mode which has been limited to long distance movements only. However, according to Freight on Rail (2005), there are a number of important short-distance links - i.e. the frequently used $30 \mathrm{~km}$ link from Greenwich to King's Cross in London. It seems intuitive therefore that diverting traffic from the roads to the railways would be one way to reduce the carbon footprint of the aggregates industry. In this section, the opportunity for a reallocation of trips from road to railways will be considered through three sub-scenarios. For each scenario, the effect on $\mathrm{CO}_{2}$ emissions are assessed. The first scenario will look at reductions in the relative cost of rail transport. The second scenario investigates improved rail linkages. The third scenario evaluates the impact of improving accessibility to the rail network by installing upload facilities for aggregates at certain key rail depots.

\subsection{Reductions in the relative cost of rail transfer (policy 1)}

A number of strategic initiatives have been introduced to encourage a switch in transport modes from road to rail in the UK. The Department for Transport committed an extra $£ 200$ million in 2014 for the development of the freight network, following an initial $£ 150$ million being assigned to increase efficiency using the 'Productivity Transport Innovation Fund 2004'. The 'Mode Shift Revenue Support Scheme' also provides a direct subsidy to rail freight transport where rail is more expensive than road. In addition to these government initiatives, steadily increasing fuel costs are likely to have had an adverse effect on the relative cost of road over rail. In this section, it is assumed that the combined effect of policy initiatives and external 
factors such as rising fuel prices is sufficient to reduce the relative cost of rail transport by $50 \%$, from the baseline of 0.31 to 0.15 .

Results from this scenario are shown in Table 3. As one might expect, reducing the cost of rail transport leads to an increase in market share for rail. The overall carbon emissions for rail naturally increase (as more is transported now by rail), but these are more than offset by an associated fall in road transport emissions. The overall impact is a reduction of 1870 tonnes of carbon emissions.

The effectiveness of this policy is still limited by the fact that the number of quarries linked to the rail network is somewhat restricted - at present, only 13 rail-linked quarries are able to upload crushed rock onto the network, and even though these are amongst the larger producers the impact of policy changes is inevitably limited. In the following scenarios these restrictions are lifted: in the first instance (policy 2) by increasing the number of rail linked quarries, and in the second instance (policy 3 ) by adding new facilities to upload aggregates from the road network onto the railways.

\section{Table 3: Summary of the Impact of Policy 1}

\begin{tabular}{lrrrrrr}
\hline & Baseline & & \multicolumn{1}{c}{ Policy 1 } & \multicolumn{3}{c}{ Change } \\
\hline & \multicolumn{1}{c}{ CR } & LSG & CR & LSG & CR & LSG \\
Relative Cost of Rail & 0.31 & 0.31 & 0.15 & 0.15 & - & - \\
Transhipment Cost & $30 \mathrm{~km}$ & $30 \mathrm{~km}$ & $30 \mathrm{~km}$ & $30 \mathrm{~km}$ & - & - \\
Market share of Rail & $11.77 \%$ & $0.23 \%$ & $13.59 \%$ & $0.24 \%$ & $1.82 \%$ & $0.01 \%$ \\
$\mathrm{CO}_{2}$ from Rail Transport (kt) & 61.19 & 0.44 & 72.75 & 0.49 & 11.56 & 0.05 \\
$\mathrm{CO}_{2}$ from Road Transport (kt) & 422.43 & 228.63 & 409.04 & 228.55 & -13.39 & -0.08 \\
$\mathrm{CO}_{2}$ from Transport (t) & 483.63 & 229.07 & 481.79 & 229.04 & -1.84 & -0.03 \\
\hline
\end{tabular}

\subsection{Increasing the number of rail-linked quarries (policy 2)}

Since the market share of rail is limited by the ability to load aggregates onto the rail network, an obvious strategy to simulate is an increase in the number of rail-linked quarries. At present only 13 of the largest quarries are linked to the rail network, of which two are for LSG and the other 11 for crushed rock.

The case for linking new quarries will be strongest for large-scale producers which are located close to the existing rail network. For this scenario, attention was limited to quarries within 10 $\mathrm{km}$ of the existing rail network. In the case of crushed rock, 36 quarries were identified with a 
production above $500 \mathrm{kt}$ per annum (data provided internally to the project by BGS). Production levels are typically less for land won sand and gravel, but 42 quarries were identified with a production above $200 \mathrm{kt}$. The total production of these quarries is $61,501 \mathrm{kt}$ and accounts for about 39\% of UK's aggregates supply (see Table 4). If each quarry can be connected to the nearest point on the rail network then an additional $261.4 \mathrm{~km}$ of track is needed, divided fairly evenly between crushed rock $(128.9 \mathrm{~km})$ and sand and gravel $(132.5 \mathrm{~km})$.

Table 4: Number and production of rail linked quarries

\begin{tabular}{lrrrrrr}
\hline & \multicolumn{1}{l}{ CR } & \multicolumn{2}{l}{ LSG } & \multicolumn{2}{l}{ Total } \\
\hline Rail-linked Quarry & No. of Quarries & Production (kt) & No. of Quarries & Production (kt) & No. of Quarries & Production (kt) \\
Existing & 11 & 18175 & 2 & 347 & 13 \\
Promoted & 36 & 31133 & 42 & 11846 & 18522 \\
Total & 47 & 49308 & 44 & 12193 & 42979 \\
\hline
\end{tabular}

In order to apply this scenario, a new set of trip assignment costs is calculated for each OD pair and the flows from the SIM are consequently updated. The outcome is a significant uplift in rail market share, from $11.77 \%$ to $16.21 \%$ for crushed rock and from $0.24 \%$ to $4.44 \%$ for sand and gravel. There is a total reduction of $35.04 \mathrm{kt}$ in carbon emissions, amounting to $4.91 \%$ of the baseline total. Note that following an earlier definition, rail market share refers to the proportion of aggregates which are transferred by that mode. Since rail trips are on average longer than road trips, the reduction in carbon emissions in this scenario is proportionately greater than the increase in rail market share. More than $76.05 \%$ of this reduction accrues to transfers of crushed rock (see Table 5).

Table 5: Summary of the impact of Policy 2

\begin{tabular}{lrrrrrr}
\hline & Baseline & \multicolumn{3}{c}{ Policy 2 } & \multicolumn{3}{c}{ Change } \\
\hline & CR & LSG & CR & LSG & CR & \multicolumn{1}{l}{ LSG } \\
Relative Cost of Rail & 0.31 & 0.31 & 0.15 & 0.15 & - & - \\
Transhipment Cost & $30 \mathrm{~km}$ & $30 \mathrm{~km}$ & $30 \mathrm{~km}$ & $30 \mathrm{~km}$ & - & - \\
Market share of Rail & $11.77 \%$ & $0.24 \%$ & $16.21 \%$ & $3.05 \%$ & $4.44 \%$ & $3.05 \%$ \\
$\mathrm{CO}_{2}$ from Rail Transport (kt) & 61.19 & 0.44 & 77.34 & 9.21 & 16.15 & 8.77 \\
$\mathrm{CO}_{2}$ from Road Transport (kt) & 422.43 & 228.63 & 379.93 & 211.38 & -42.5 & --17.25 \\
$\mathrm{CO}_{2}$ from Transport (kt) & 483.63 & 229.07 & 457.28 & 220.58 & -26.55 & -8.49 \\
\hline
\end{tabular}

In this analysis, the economic and environmental costs to establish the scenario are not modelled explicitly, but are clearly considerable. In particular, given that more than half of the new quarries are for sand and gravel and that more than half of the new track is devoted to connections for sand and gravel, the relative impact in this sector is rather disappointing. The 
case for linking crushed rock quarries is evidently somewhat stronger, although it must still be noted here that the setup costs are considerable. Whether such a scenario is viable depends to some extent on a full economic and environmental appraisal which is beyond the scope of the current paper; but still the impact on carbon emissions is an important reference point against the other scenarios which will be considered.

\subsection{Extended Uploading Facilities (policy 3)}

In Section 3 above, we noted that the ability to transfer distribution from roads to railways is limited by restrictions in the linkages from quarries to the rail network, given that only 13 of the largest quarries have the capability to upload aggregates directly onto the rail network (12 of which are for crushed rock and 2 for sand and gravels). A third scenario is to investigate the effect of extending this network by adding uploading facilities to each of the 63 rail depots. This has the effect of allowing a new sequence in the distribution process of quarry-road-depotrail-depot-road-consumer. In addition to assuming that every rail depot now has upload facilities, the transhipment cost for uploading is taken to be the same as the cost of downloading.

Following implementation of this scenario, there is an increase in the market share of rail for both crushed rock and sand and gravel, amounting to approximately $3 \%$ in the case of crushed rock and slightly less for sand and gravel, as shown in Table 6. Increased carbon emissions of $14.04 \mathrm{kt} \mathrm{CO}_{2}$ by rail are offset by reductions of approximately $18.64 \mathrm{kt}$ on the roads, thus a net saving in the order of $4.42 \mathrm{kt}$.

Table 6: Summary of the impact of Policy 3

\begin{tabular}{lrrrrrc}
\hline & Baseline & & \multicolumn{1}{c}{ Policy 3 } & \multicolumn{3}{c}{ Change } \\
\hline & CR & LSG & CR & LSG & CR & \multicolumn{1}{c}{ LSG } \\
Relative Cost of Rail & 0.3 & 0.3 & 0.15 & 0.15 & - & - \\
Transhipment Cost & $30 \mathrm{~km}$ & $30 \mathrm{~km}$ & $30 \mathrm{~km}$ & $30 \mathrm{~km}$ & - & \multicolumn{1}{c}{-} \\
Market share of Rail & $11.77 \%$ & $0.24 \%$ & $13.60 \%$ & $1.15 \%$ & $1.83 \%$ & $0.91 \%$ \\
$\mathrm{CO}_{2}$ from Rail Transport (kt) & 61.19 & 0.44 & 72.73 & 2.94 & 11.54 & 2.50 \\
$\mathrm{CO}_{2}$ from Road Transport (kt) & 422.43 & 228.63 & 409.10 & 223.50 & -13.33 & -5.13 \\
$\mathrm{CO}_{2}$ from Transport (kt) & 483.63 & 229.07 & 481.83 & 226.45 & --1.80 & -2.62 \\
\hline
\end{tabular}

The infrastructure investment required for the addition of new uploading facilities is likely to be considerably less than the requirements for new track (and uploading facilities) implied by 
policy 2. On the other hand, the benefits are also reduced in carbon terms by about three quarter. The reasons for this relatively limited impact are twofold. First, the pattern of distribution which is needed to reallocate transfers to rail is rather convoluted, and now includes a road component at both ends. Hence two sets of transhipment cost are now incurred for each trip, and this makes the economic cost rather unattractive. Second, the distribution of rail depots themselves is not conducive to efficient distribution by this means. Since the depots have been designed with the primary intention of downloading to the road network, they are mostly located close to the major cities, and not close to the quarries. This means that it still takes quite a lot of effort to get aggregates onto the railways, and that once there the distance to its final destination is not necessarily substantial. It seems that a much more extensive and even distribution of rail depots would be needed to allow significant carbon footprint impacts.

\section{What-if modelling (2): scenarios based on changes to the road haulage fleet}

\subsection{Overview}

In the previous section a number of scenarios to encourage the transfer of aggregates from road to railways were considered. It was concluded that the market share for rail could potentially be doubled from the current $10 \%$ but only at the cost of a considerable investment in new infrastructure. A different set of options is investigated next in order to determine whether better results could be achieved by changes in the technology of HGVs. Two possibilities will be considered - in the first, a change in vehicle emission standards (policy 4), and in the second, a change in the size and type of vehicles in the road fleet (policy 5).

\subsection{Impacts of changing policies on emission regulations (policy 4)}

To explore both policy options for road, a vehicle replacement component was introduced to the HGV simulation model. Here, we borrowed the concept of mortality and fertility rates from demographic studies. In this case, the mortality rate of a HGV refers to the rate at which a 
vehicle is likely to be withdrawn from the freight market in the next year (a vehicle 'death'). Each HGV that 'dies' is effectively replaced by a new vehicle (a 'birth'). Obviously, a higher mortality rate can be expected for an older vehicle. Firstly, we identified 'mortality rates' for vehicles by age between 2001 and 2007 (Department for Transport 2009) - see Figure 5. These patterns are broadly consistent from year to year, with steadily increasing rates of mortality with age, until some fluctuations begin to set in for the most elderly vehicles due to small number issues. Therefore, a linear model (equation 8) was introduced to represent the mortality-age relationship $\left(\mathrm{R}^{2}=0.95\right)$ (due to the small number of vehicles aged $15+$, only the data for HGVs aged less than 16 were used for the regression analysis). Put simply, the older the vehicle is the more chance it has of being withdrawn. The maximum age is 56 when a vehicle must be withdrawn. However, in reality most vehicles over 15 years are likely to be withdrawn due to a cumulative effect through years (as the probability quickly rises).

$$
\text { Mortality Rate }=\left\{\begin{array}{cc}
0.0178 * \text { Age }+0.0005 & 0<\text { Age }<56 \\
1 & \text { Age }=56
\end{array}\right.
$$

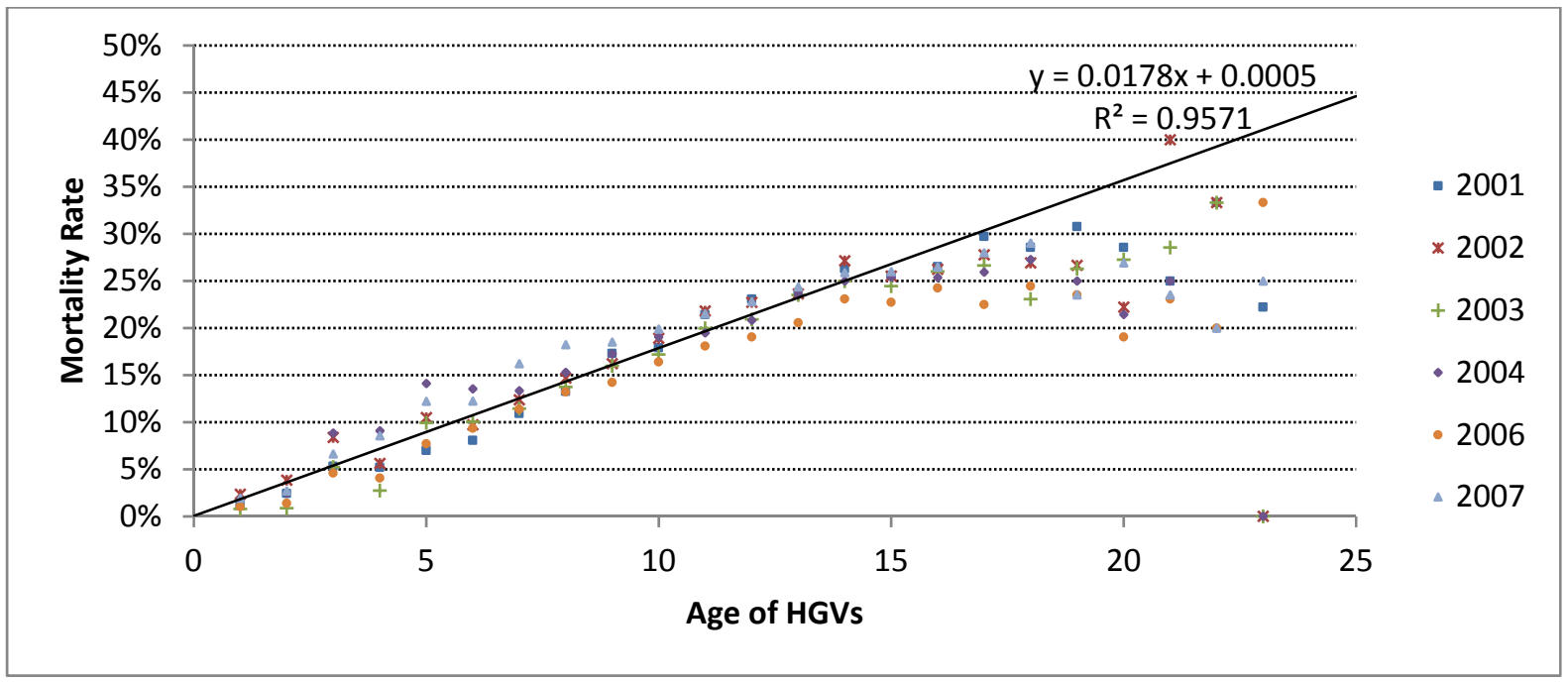

Figure 5: Mortality rates vs. age of HGVs

All vehicles which 'die' are replaced with a vehicle of equivalent specification, except that all new vehicles must meet the Euro V emission standard which was introduced in October 2008. 87,100 vehicles are affected by this change during our time period. The outcomes from this scenario, policy 4, are shown in Tables 7 and Figure 6. Clearly, and unsurprisingly, there is a shift in the vehicle population towards Euro V and away from Euro II, IV and particularly III. There is a slight reduction in the proportion of rigid vehicles, reflecting existing demographic variations (i.e. a slightly more elderly age profile amongst rigid vehicles). The results suggests 
that evolution of the European emission standards has some positive impacts on carbon emissions. With more vehicles with higher emission standard replaced the old ones, the carbon emission associated with the road transport reduced accordingly, but with only a limited effect. The modelling results shows about $14.65 \mathrm{kt}$ of the carbon emission was saved in 2017 compare to the level of 2008.

Table 7: Number of vehicles with different emission standard from 2008 to 2018 (policy 4)

\begin{tabular}{|c|c|c|c|c|c|c|c|c|c|c|c|c|}
\hline & \multicolumn{2}{|c|}{2008} & \multicolumn{2}{|c|}{$2010 a$} & \multicolumn{2}{|c|}{ 2012a } & \multicolumn{2}{|c|}{$2014 a$} & \multicolumn{2}{|c|}{ 2016a } & \multicolumn{2}{|c|}{$2018 a$} \\
\hline $\begin{array}{l}\text { Euro } \\
\text { Std. }\end{array}$ & $\begin{array}{l}\text { No. } \\
(\times 1000)\end{array}$ & $\%$ & $\begin{array}{l}\text { No. } \\
(\times 1000)\end{array}$ & $\%$ & $\begin{array}{l}\text { No. } \\
(x 1000)\end{array}$ & $\%$ & $\begin{array}{l}\text { No. } \\
(\times 1000)\end{array}$ & $\%$ & $\begin{array}{l}\text { No. } \\
(\times 1000)\end{array}$ & $\%$ & $\begin{array}{l}\text { No. } \\
(x 1000)\end{array}$ & $\%$ \\
\hline Pre-I & 12.5 & 2.87 & 8.2 & 1.88 & 1.6 & 0.37 & 0.3 & 0.07 & 0.1 & 0.02 & 0 & 0.00 \\
\hline I & 14.2 & 3.25 & 6.1 & 1.4 & 3.1 & 0.71 & 1.8 & 0.41 & 0.8 & 0.18 & 0.2 & 0.05 \\
\hline II & 46.5 & 10.66 & 30.1 & 6.9 & 15.9 & 3.64 & 8.3 & 1.90 & 4.4 & 1.01 & 2.1 & 0.48 \\
\hline III & 180 & 41.23 & 134 & 30.78 & 92.1 & 21.11 & 55.3 & 12.67 & 33.8 & 7.75 & 17.6 & 4.03 \\
\hline IV & 183 & 41.99 & 17 & 39.08 & 132.9 & 30.46 & 102.1 & 23.40 & 73 & 16.73 & 47.2 & 10.82 \\
\hline V+ & 0 & 0 & 87.1 & 19.96 & 190.7 & 43.71 & 268.5 & 61.54 & 324.2 & 74.31 & 369.2 & 84.62 \\
\hline
\end{tabular}

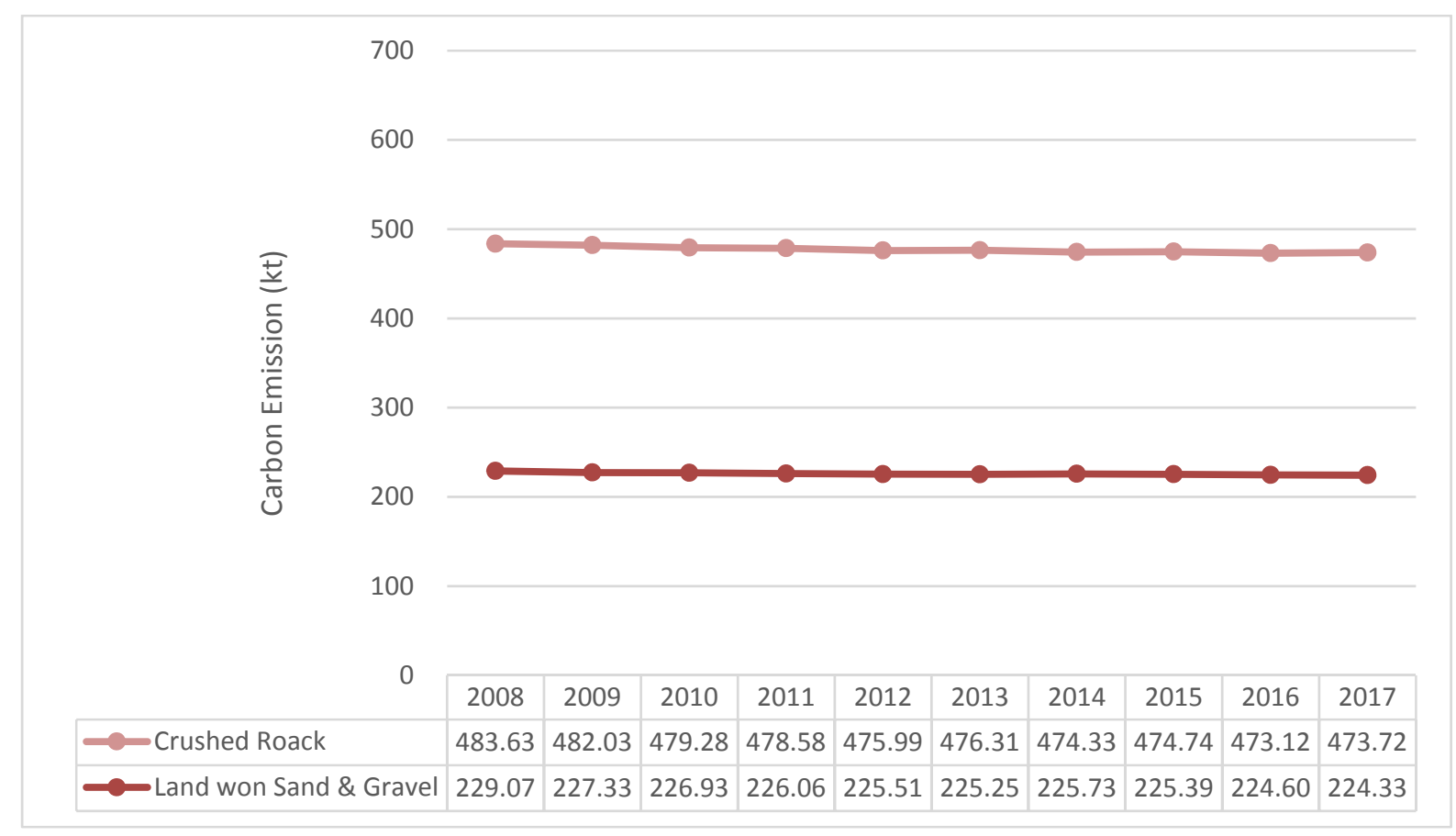

Figure 5: Carbon Emission by Aggregates Type under Policy 4

\subsection{Introducing more articulated vehicles (policy 5)}

The second policy option is the replacement of vehicle types (policy 5). There has been a long term debate as to whether the introduction of articulated vehicles can reduce carbon emissions 
(SKM, 2002) and within the last year the Road Haulage Association in the UK has lobbied heavily for use of longer, 18 metre (articulated) vehicles.

In this scenario we assume that when vehicles 'die' they are replaced by articulated vehicles whose type is assigned randomly from the existing vehicle population (and the Euro V standard is also adopted by all new vehicles). Thus the vehicle profile by emission standards is retained from Table 7 above, but the profile by body type changes substantially as shown in Table 8 . In $2010,65,000$ vehicles - amounting to about $15 \%$ of the vehicle fleet - have in effect been converted from rigid to articulated over the time period, and the proportion of much more efficient articulated vehicles in the fleet has risen to well over $40 \%$ in 2010 and almost $90 \%$ at 2018.

Table 8: Number of vehicles with different body type in 2008 and 2010 (policy 5)

\begin{tabular}{|c|c|c|c|c|c|c|c|c|c|c|c|c|}
\hline \multirow[b]{2}{*}{$\begin{array}{l}\text { Body } \\
\text { Type }\end{array}$} & \multicolumn{2}{|c|}{2008} & \multicolumn{2}{|c|}{ 2010a } & \multicolumn{2}{|c|}{ 2012a } & \multicolumn{2}{|c|}{$2014 a$} & \multicolumn{2}{|c|}{ 2016a } & \multicolumn{2}{|c|}{ 2018a } \\
\hline & $\begin{array}{l}\text { No. } \\
\text { (x1000) }\end{array}$ & $\%$ & $\begin{array}{l}\text { No. } \\
\text { (x1000) }\end{array}$ & $\%$ & $\begin{array}{l}\text { No. } \\
(\times 1000)\end{array}$ & $\%$ & $\begin{array}{l}\text { No. } \\
(x 1000)\end{array}$ & $\%$ & $\begin{array}{l}\text { No. } \\
\text { (x1000) }\end{array}$ & $\%$ & $\begin{array}{l}\text { No. } \\
\text { (x1000) }\end{array}$ & $\%$ \\
\hline Rigid & 315 & 72.20 & 250 & 57.32 & 179 & 40.91 & 127 & 28.99 & 84 & 19.18 & 47 & 10.73 \\
\hline Artic & 121 & 27.80 & 186 & 42.68 & 258 & 59.09 & 310 & 71.01 & 353 & 80.82 & 390 & 89.27 \\
\hline
\end{tabular}

The impact of these changes on carbon emissions is much more positive. There is a substantial reduction in carbon emissions from the transfer of both crushed rock and land-won sand and gravel. According to Figure 7, the reduction of carbon emission will achieve 85.22kt at 2013. This value is even higher than the reduction of carbon emission with Policy 2 which is the best case scenario with rail transport. If the policy continues, the savings from this policy amount to around $112.65 \mathrm{kt}$ at 2017 . This is a reduction of $15.8 \%$ from the baseline model, or $14 \%$ compared to Road Scenario A (policy 4). 


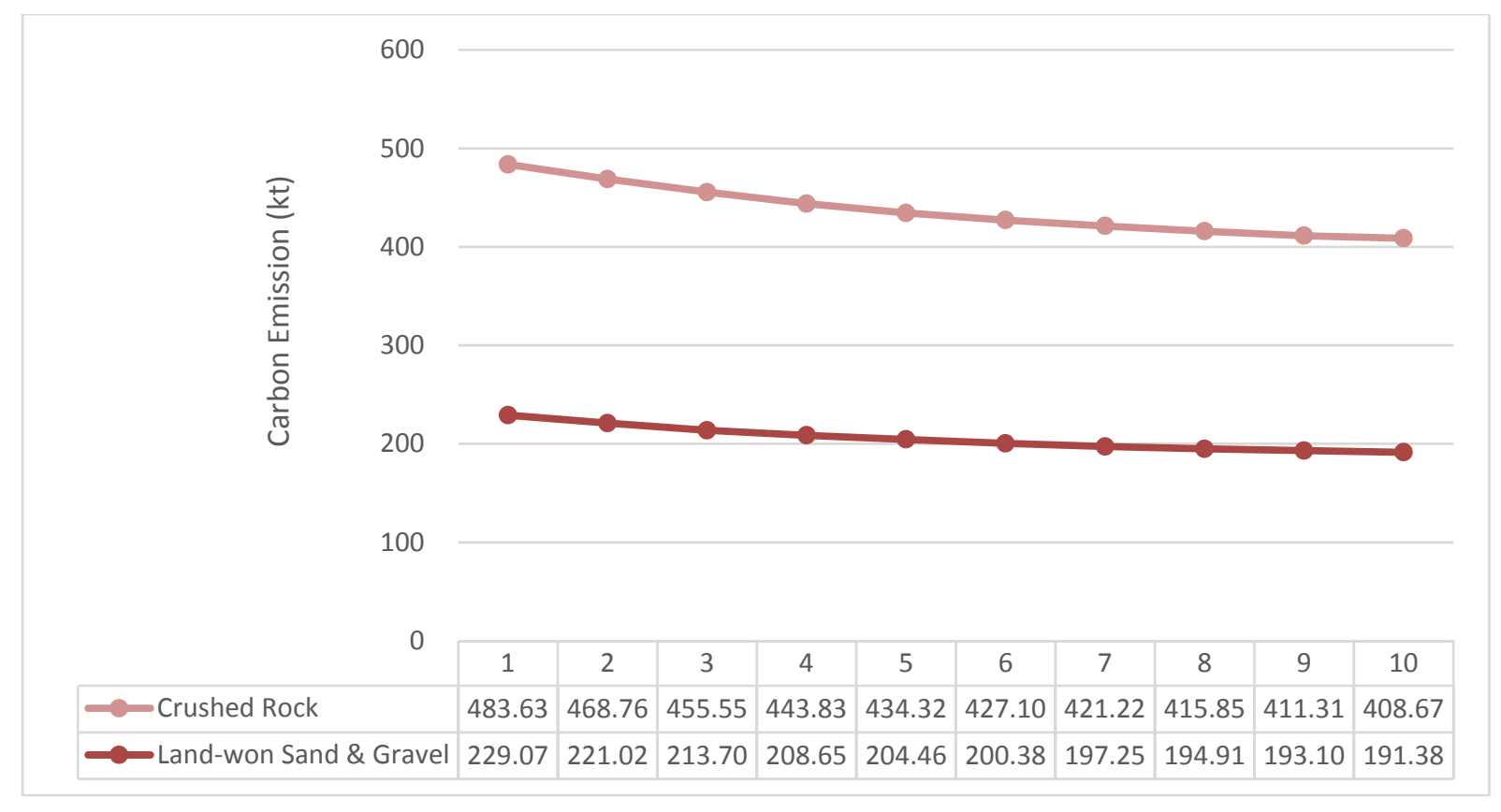

Figure 6: Carbon Emission by Aggregates Type under Policy 5

\section{Conclusions and discussion}

In this paper we have provided a modelling framework for estimating the carbon emissions associated with both road and rail for the UK aggregates industry. This has been based on a combination of spatial interaction modelling and spatial (micro)simulation modelling. Through the representation of individual flow patterns, from the point of production to the point of consumption, it is possible to construct a model of the transportation of aggregates from the bottom up, and once this has been done the associated carbon emissions can be computed with relative ease. Using this framework we have then been able to model a variety of scenarios to look at the impacts of both changing the balance between road and rail, and of improving the efficiency of the HGV fleet for road transportation.

It is interesting to note that although a very substantial reduction of $50 \%$ in the relative cost of rail transport (in effect a doubling in the relative cost of road transport) leads to a less than $1 \%$ reduction of emissions, the equivalent savings are more than $15 \%$ through changing the composition of the HGV fleet (over a relatively short period of time). In addition, introducing expensive solutions with the introduction of new rail linked quarries and additional upload facilities at rail depots cannot match these savings. 
In view of the dominant existing share of road transport (and its position as the most versatile and preferred mode of distribution for aggregates haulage) it seems that policies directed to the road haulage industry itself rather than its rail competitor may be of greatest potential for the reduction of carbon emissions. We found that upgrading to an apparently higher Euro emissions standard was relatively unsatisfactory because the later standards are actually less rigorous than those they replaced. However policies to encourage changes to the vehicle fleet were found to generate carbon reductions in the order of twice as great as the most favourable rail scenarios.

It could be argued that the calibration data which have been used in this exercise are indirect they lack precision in both their measurement and relevance (for example relative cost of rail has been estimated in relation to a single model split observation between road and rail from 2005). It is certainly true that more accurate data could be introduced here, although there could also be issues associated with availability/ sustainability (e.g. or quarry outputs) and cost of acquisition (e.g. lorry movements might potentially be acquired via sensors or satnav. While this might be consonant with the 'big data' agenda (Lovelace et al, 2016), it would also be complex and expensive). Against this we would argue that more detailed evidence has been included where it makes the biggest difference in spatial disaggregation of the aggregates supply chain - and that this detail is more than sufficient to support the conclusions of the paper. For example, one might estimate a more accurate or updated value of the average distance parameter, and this might make the model outputs fractionally more robust; but it is highly unlikely that it would alter the fundamental conclusion that rail cannot compete effectively with road for short-haul transfers, whether costs are measured economically (in pounds sterling) or environmentally (as a carbon footprint).

Many more scenarios could be modelled and tested. Indeed, there could be a number of alternative modelling options which might arise from alternative policy regulations brought in to regulate the road haulage fleet in the future (Tight et al 2005, Piecyk and McKinnon, 2010, and Hickman and Banister 2007, Yang et al 2009 provide some interesting examples). We hope the framework outlined in this paper will be flexible enough for the BGS to be able to use this framework to test a whole suite of alternative policy options for the future.

\section{Acknowledgement}


This research was supported by the BGS-University of Leeds joint research scholarship, and by the Fundamental Research Funds for the Central Universities under project 2662016QD019.

\section{References}

Barlow, T. J. and Boulter, P. G., 2009, Emission factors 2009: Report 2 - a review of the average speed approach for estimating hot exhaust emissions.

Birkin M, Clarke G, Clarke M (2010) Refining and operationalising entropy maximizing models for business applications, Geographical Analysis, 42(4), 422-445.British Geological Survey, 2006, Planning 4 Minerals A Guide on Aggregates, Entec UK Ltd, Shrewsbury

Boston Consulting Group, 2009, Aggregates Sector Strategy Review, Final report by the Boston Consulting Group, London, UK.

Boulter, P. G. , Barlow, T. J. and McCrae, 2009, Emission factors: Report 3 - exhaust emission factors for road vehicles in the United Kingdom. TRL Report PPR256. TRL Limited, Wokingham.

Cameron, D.G., 2011, User Guide for the BRITPITS dataset, British Geological Survey Open Report, OR/11/07. Nottingham

Chapman, L, 2007, Transport and climate change: a review, Journal of Transport Geography, 15(5), pp 354-367

Chow, J.Y.J. Yang, C.H., and Regan, A.C., 2010, State-of-the art of freight forecast modelling: lessons learned and the road ahead, Transportation, 37, pp. 1011-1030

Cortés, C. E., Pagès, L., and Jayakrishnan, R., 2005, Microsimulation of flexible transit system designs in realistic urban networks. Transportation Research Record: Journal of the Transportation Research Board, 1923(1), 153-163.

de Jone, G., Gunn, H.F. and Walker, W., 2004, National and international freight transport models: an overview and ideas for further development. Transport Reviews, 24(1), pp.103124

de Jone, G, Vierth. I., Tavasszy, L. and Ben-Akiva, M., 2013, Recent developments in national and international freight transport models within Europe, Transportation, 40, pp. 347-371

Department for Community and Local Government, 2007, Collation of the results of the 2005 Aggregate Minerals Survey for England and Wales, DELG, London

Department for Environment, Food and Rural Affairs, 2005, The UK Government Sustainable Development Strategy, HMSO, Norwich

Department for Environment Food and Rural Affairs, 2008, 2008 Guidelines to Defra's GHG Conversion Factors: Methodology Paper for Transport Emission Factors. Defra, London 
Department for Energy and Climate Change, 2009, The UK Low Carbon Transition Plan National strategy for climate and energy, OPSI, Surry

Department for Transport, 2005, Department for Transport - NERA report on lorry track and environment costs, DfT, London

Department for Transport, 2008, Factsheets UK Transport and Climate Change data, DfT, London.

Department for Transport, 2009, Transport Statistics Bulletin Road Freight Statistics 2008, DfT, London

Freight on Rail, 2005, Rail freight Fats and Myths, Available at: http://www.freightonrail.org.uk/PDF/FactsandMyths.pdf. Access Data: 10/06/2014

Hickman R., and Banister D., 2007, Looking over the horizon: transport and reduced CO2 emissions in the UK by 2030, Transport Policy, 14, pp.377-387

Harris, N.G. and McIntosh, D., 2003, The economics of rail transport N.G. Harris, F. Schmid (Eds.), Planning Freight Railways, A\&N Harris, London

Highley, D.E., Hetherington, L.E., Brown, T.J., Harrison, D.J., Jenkins, G.O., 2007, The Strategic Importance of the Marine Aggregate Industry to the U.K. BGS Research Report OR/07/019, Nottingham

Hicks, L., 2012, A Synthesis of the issues for policy makers raised by the Aggregates Strategic Research Programme 2009 to 2011, Available at: http://www.sustainableaggregates.com/library/docs/10593 synthesis report.pdf. Access Date $13 / 07 / 2016$

Knudsen, D.C. and Fotheringham, A.S., 1986, Matrix Comparison, Goodness-of-Fit and Spatial Interaction Modelling, International Regional Science Review, 10 (2), pp.127-147

Liu, R., 2005, The DRACULA dynamic traffic network microsimulation model, in Simulation Approaches in Transportation Analysis: Recent Advanced and Challenges (ed. Kitamura and Kuwahara), pp 23-56, Springer, 2005.

Lovelace, R., Birkin, M., Clarke, M., Cross, P. (2016) From Big Noise to Big Data: Towards the Verification of Large Datasets for Understanding Regional Retail Flows, Geographical Analysis, 48, 59-81.

McKinnon A.C. and Piecyk M.I., 2009, Measurement of CO2 emissions from road freight transport: a review of UK experience, Energy Policy, 37, 3733-3742

Mineral Products Association, 2009, Mineral Products Association Sustainable Development Report 2009, Available at:

http://www.mineralproducts.org/sustainability/pdfs/MPA_SD Report 2009.pdf, Access

Date: $20 / 10 / 2013$

Mineral Products Association, 2010, Aggregate Portal Hard Rock Quarry Case Study, Available at:

http://www.aggregatescarbonreduction.com/resources/case studies/Quarry Case Study 2.0. pdf, Access Date: 23/08/2011 
Mineral Products Association, 2011, Accelerating progress...meeting the challenges Summary Sustainable Development Report 2011, Available at:

http://www.mineralproducts.org/sustainability/pdfs/SD_Summary_Report_2011.pdf, Access

Date: $13 / 07 / 2016$

Mineral Products Association, 2013, Engagement and delivery... a continuing commitment Summary Sustainable Development Report 2013, Available at: http://www.mineralproducts.org/sustainability/pdfs/2013 MPA main SD report single.pdf, Access Date: 13/07/2016

Mineral Products Association, 2015, Summary Sustainable Development Report 2015 Progress and momentum... continuing commitment, Available at: http://www.mineralproducts.org/sustainability/pdfs/MPA_SD_Report 2015.pdf, Access Date: $13 / 07 / 2016$

Musti, S. and Kockelman, K. M., 2011, Evolution of the household vehicle fleet: Anticipating fleet composition, PHEV adoption and GHG emissions in Austin, Texas. Transportation Research Part A: Policy and Practice, 45(8), 707-720.

Neffendorf, H., M. Wigan, R. Donelly, I. Williams and M. Collop (2001) The emerging form of freight modelling, Paper presented at 2001 European Transport Conference, Cambridge.

Piecyk M.I. and McKinnon A.C., 2010, Forecasting the carbon footprint of road freight transport in 2020, International Journal of Production Economics, 128, 31-42

Quarry Products Association, 2006, QPA Sustainable Development Report 2005 Update, Grillingham House, London

Sinclair Knight Merz, 2002, Commission for Integrated Transport Rail freight: delivering on growth Final Report, Project Reference: EU00168, London

Strategic Rail Authority, 2005, Aggregates Market Study: Summary Report Strategic Rail Authority, Freight Team, London

Tight M.R., Bristow A.L., Pridmore A. and May A.D., 2005, What is a sustainable level of CO2 emissions from transport activity in the UK in 2050? Transport Policy, 12, 235-244

UK Minerals Forum, 2009, Shaping UK minerals policy, UK Minerals Forum, London

Vovsha, P., Petersen, E., and Donnelly, R., 2002, Microsimulation in Travel Demand Modeling: Lessons Learned from the New York Best Practice Model. Transportation Research Record 1808, pp. 68-77.

Yang C., McCollum D., McCarthy R and Leighty W., 2009, Meeting an 80\% reduction in greenhouse gas emissions from transportation by 2050: a case study in California, Transportation Research D, 14, 147-156

Zuo,C., Birkin, M., Clarke, G.P, Fiona, M. and Bloodworth, A., 2013, Spatial modelling, GIS and network analysis for improving the sustainability of transporting aggregates in the UK. In Stimson,R., and Haynes, K., (ed.) Studies in Applied Geography and Spatial Analysis:

Addressing Real World Issues, Edward Elgar, Cheltenham, UK, 55-78 